Results Significant main effects of gender $(\mathrm{F}=8.777$; $\mathrm{p}<0.01)$ and age $(\mathrm{F}=3.092 ; \mathrm{p}<0.01)$, as well as an interaction effect of these two factors $(\mathrm{F}=3.043 ; \mathrm{p}<0.05)$ were found. Girls show higher levels of social concerns, unsteady concerns and disease concerns, while risky behaviours and peer problems are more prevalent in boys. Results also show that risky behaviours in age-group 14 and up are less prevalent in boys, and more prevalent in girls.

Conclusion This study shows that girls have a higher anxiety sensitivity level, while boys exhibit more behaviour difficulties, which the authors of the study speculate is the result of cultural differences and gender based expectations. Results also show that social concern and peer problems depend on age.

\section{P0-0936 ADOLESCENTS IN PAEDIATRIC WARDS: WHAT DO THEY REALLY THINK?}

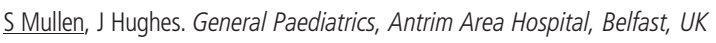

10.1136/archdischild-2014-307384.1557

Aims To review current adolescent opinion regarding a recent admission to the paediatric ward in Antrim Area Hospital.

Methods A questionnaire was posted to all 11-18 year old patients who were admitted to the Paediatric Ward in Antrim Area Hospital from July 2012- Sept 2012.

The questionnaire was re-posted after 4 weeks to those who had failed to return the initial form.

Results Returns 50/109 (46\%); 29 surgical patients and 21 paediatric medical patients.

$84 \%$ stated that their care was good or very good. $80 \%$ felt they had a good understanding of the reason for admission. $84 \%$ felt the medical staff took their opinion of board when deciding treatment plans.

$46 \%$ stayed in a bay with patients a lot younger than themselves with $74 \%$ preferring to stay in a bay with patients their own age group. $70 \%$ were bored some or most of the time. $76 \%$ were happy with the level of privacy while $22 \%$ felt it could have been better.

$2 \%$ had a question they wanted to ask but didn't, while $6 \%$ would have liked to have been able to speak to someone in private but felt they didn't have the opportunity to. 14\% felt they could not speak to the medical team, either due to concerns about confidentiality or other reasons.

Conclusions Confidentiality and where to place adolescences are important areas we must consider when planning future development.

\section{P0-0937 MEASUREMENT OF LEVEL OF SOCIAL SUPPORT AND BURNOUT PERCEIVED BY MOTHERS WITH MENTALLY DISABLED CHILDREN}

${ }^{1}$ I Kahriman, ${ }^{2} \underline{S}$ Polat, ${ }^{3} \mathrm{G}$ Daar. ${ }^{1}$ Nursing, Karadeniz Technical University School of Healthy, Trabzon, Turkey; ${ }^{2}$ Nursing, Bozok University School of Healthy, Yozgat, Turkey; ${ }^{3}$ Pediatrics, Bozok University Faculty of Medicine, Yozgat, Turkey

\subsection{6/archdischild-2014-307384.1558}

Introduction Having a mentally disabled child may bring some challenging situations alongside the caring period. Mothers are affected in most of times due to these experienced difficulties and during this challenging period mothers who couldn't get enough social support can suffer from burnout syndrome.

Methods This study was carried out among mothers with mentally disabled children between March and June 2011 to measure level of social support given and fatigueness perceived by mothers. Mothers with mentally disabled children living in city centre of Trabzon who were given special education in primary level of public schools $(n=128)$ were included in the study. The data was gathered by using mother-and-child introductory forms, Maslach burnout inventory, Multidimensional Scale of Perceived Social Support (MSPSS).

Results $40.6 \%$ of mothers involved in the study were above 40 years old. It was found that average score of emotional exhaustion subscale of Maslach Burnout Inventory (MBI) was $14.5 \pm$ 7.6, average low personal accomplishment and depersonalization scores of MBI were $9.7 \pm 5.7$ and $4.5 \pm 3.7$ accordingly.

Other average significant subscale score of MSPSS was 19.9 \pm 8.0 , additionally it was found that average friend subscale and family subscale scores of MSPSS were $8.2 \pm 8.6$ and $20.0 \pm 7.9$ respectively. MSPSS scores and BMI scores of the mothers was found to be significantly correlated to each other.

Conclusion In the study, mothers were found to have moderate level of perceived social support and had burnout feelings. It is advised that mothers with mentally disabled children should get more social support.

\section{PO-0938 THE EFFECT OF VISUAL DAY-DREAMING AND MUSIC THERAPY ON REDUCING THE TEST ANXIETY OF THE UNIVERSITY STUDENTS}

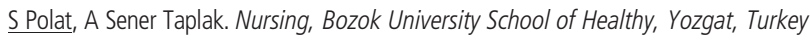

\subsection{6/archdischild-2014-307384.1559}

Introduction Test anxiety is a different form of situational anxiety. Although it is favourable as long as it motivates the students to learn, extreme levels of it can cause academic failure and psychological problems on the part of the individual.

Method This is a randomised controlled experimental study which aims at investigating the effect of visual day-dreaming and music therapy on reducing the test anxiety of the university students. The sample of the study consisted of 84 voluntary students, all of whom were included in the study. The students were selected on the basis of simple random sampling to form three different working groups: visual day-dreaming group, music therapy group and the control group. The data were collected by means of an information form about the participant's socio-demographic characteristics, their day-dreaming and musical preferences, and a scale for situational and persistent anxiety. Results The students in the three groups were found to be homogenous in terms of age, gender, marital status, income, and the place of longest stay. The mean scores of persistent anxiety for the students in visual day-dreaming group, music therapy group, and the control group were all found to be high. Statistically significant differences were observed between the three groups in terms of their mean scores of situational anxiety.

Conclusion In this study, it was determined that visual daydreaming was found to reduce university students' test anxiety, with significantly lower anxiety scores gauged from the daydreaming group than the control group.

\section{PO-0939 POST-TRAUMATIC SYMPTOMATOLOGY AND ATTACHMENT MODELS AMONG CHILDREN AND ADOLESCENTS WITH SOMATIC SYMPTOM DISORDERS}

F Bizzi, R Castellano, D Cavanna. Department of Educational Sciences, University of Genoa, Genoa, Italy

10.1136/archdischild-2014-307384.1560 
Background In line with a consistent literature, somatic symptom disorders (having pronounced somatic symptoms without objective somatic signs) in childhood and adolescence have experienced traumatic events, such as physical or sexual abuse, major loss, natural disasters or who have been witnesses to violence. Recent studies are focusing the attention on the role of attachment and post-traumatic symptomatology for a better evaluation of this disorder.

Objective The following objectives are set by the present study: 1) to evaluate the post-traumatic stress and related psychological symptomatology in a group of children diagnosed with somatic symptom disorders; 2) to evaluate their attachment models; 3) to test the extent of the association between post-traumatic symptomatology and attachment organisation in somatic symptom disorders.

Method Twenty consecutive Italian patients aged from 8 to 15 $(\mathrm{m}=11,9 ; \mathrm{ds}=1,48)$, previously diagnosed with somatic symptom disorders, were administered the Trauma Symptom Checklist for Children (TSCC-A) and the Child Attachment Interview (CAI).

Results Post-traumatic symptomatology, evaluated in 9 subscales, showed clinically significant scores about anxiety, depression and post-traumatic stress; dissociation symptomatology was seen only in $5 \%$ of the patients. Insecure attachment was found in more than half of the patients diagnosed with somatic symptom disorders.

Conclusions This study suggests that attachment organisation may be a fundamental element to be assessed in the evaluation of somatic symptom disorders in children and adolescents. Finally, methodological limitations restricting causal inferences between attachment and dissociation are discussed.

\section{P0-0940 INFLUENCE OF FERROTHERAPY ON PSYCHOMOTOR DEVELOPMENT OF CHILDREN OF YEARLY AGE WITH IRON DEFICIENCY ANAEMIA}

${ }^{1} \mathrm{~K}$ MatiaSvili, ${ }^{2} \mathrm{~N}$ Manjavidze, ${ }^{3} \mathrm{~T}$ Ghongadze, ${ }^{2} \mathrm{~N}$ Adamia, ${ }^{2} \mathrm{M}$ Ghughunishvili. ${ }^{1} \mathrm{M}$. lashvili Children's Central Hospital, Department of General Pediatrics, Tbilisi, Georgia; ${ }^{2}$ Tbilisi State Medical University, Tbilisi, Georgia; ${ }^{3}$ I. Tsitsisshvili Children Hospital, Department of General Pediatrics, Tbilisi, Georgia

10.1136/archdischild-2014-307384.1561

According to universally acknowledged biopsychosocial model of development, numerous biological and environmental factors influence development of children. One of them is iron deficiency in the organism. The study assessed physical, motor and psychosocial development of children who at an early age had the diagnosis of iron deficiency anaemia and had been treated by iron drugs. Their neurological, receptive, expressive and cognitive functions were assessed using BINS (Bayeley's Infanft's Neurodevelopmental Screen). The sample was divided into 2 age groups: 16-20 and 21-24 months.

The study shows that in children, who had iron deficiency at an early age and had taken treatment with relevant drugs in a timely manner, the aggregate indicators of four clusters do not differ significantly from standard indicators submitted by BINS. We deem important time diagnosis of iron deficiency and beginning of respective treatment, in order to avoid problems in psychomotor development; Timely treatment will favour the processes of development of child's social and school preparedness.

\section{PO-0941 THE CAUSES OF PSYCHOSOMATIC DISORDERS IN CHILDREN}

${ }^{1} \mathrm{~N}$ Makieieva, ${ }^{1} \mathrm{~A}$ Penkov, ${ }^{1} \mathrm{R}$ Marabyan, ${ }^{2} \mathrm{M}$ Kholodova, ${ }^{2}$ Vasheva. ${ }^{1}$ Pediatrics \#1 and Neonatology, Kharkov National Medical University, Kharkov, Ukraine; ${ }^{2}$ Neurology, Kharkov Region Children's Clinical Hospital, Kharkov, Ukraine

10.1136/archdischild-2014-307384.1562

Background and aims The causes of psychosomatic disorders in children are in a family attitude towards a child and the relationship between parents. The understanding of 'family psychological health' will allow creating strategies to prevent and treat psychosomatic disorders in children.

Aims To define the types of family disorganisation and psychological adaptation features of preschoolers living in families.

Methods The questioning on the test ' $\mathrm{ABC}$ for parents and children aged 3-10 years' the parents of 36 preschoolers with psychosomatic symptoms was held. We studied the level of parental protection in upbringing, the degree of the child's needs satisfaction, the number and quality requirements to the child in a family, instability of parenting style. The daily urine free cortisone concentrations were investigated.

Results The upbringing peculiarities which promote to deviation's development in behaviour and psychosomatic diseases development were found in $91,6 \%$ of children: due to hyperprotection (in 52,8\%) and hypoprotection (in 38,8\%). The hyperprotection of children is related to the expansion of parental feelings (56\%), upbringing insecurities of parents (61\%). In half of the families there is a projection of undesirable qualities of the parents to the child. The elevation of daily urine free cortisone excretion in children with hypoprotection compared with hyperprotection were determined $((18.2(16.0 ; 18.6)$ and 16.7 $(15.5 ; 17.7) \mathrm{nmol} / \mathrm{nmol}$ in creatinine, respectively $(\mathrm{p}<0.05))$.

Conclusions These data suggest that the paediatrician should pay attention not only to physical health of the child, but also the psychological. The timely correction of upbringing will reduce the frequency of psychosomatic illnesses.

\section{PO-0942 LEVEL OF ANXIETY IN MOTHERS WITH SICK CHILDREN APPLYING TO THE HOSPITAL IN AN OUTPATIENT SETTING}

${ }^{1} \mathrm{G}$ Daar, ${ }^{2} \mathrm{Al}$ Gül, ${ }^{3} \mathrm{H}$ Ede, ${ }^{4} \mathrm{~S}$ Polat, ${ }^{5} \mathrm{M}$ Ozdamar. ${ }^{1}$ Pediatrics, Bozok University Faculty of Medicine, Yozgat, Turkey; ${ }^{2}$ Psychiatry, Bozok University Faculty of Medicine, Yozgat, Turkey; ${ }^{3}$ Cardiology, Bozok University Faculty of Medicine, Yozgat, Turkey; ${ }^{4}$ Nursery, Bozok University School of Health Sciences, Yozgat, Turkey; ${ }^{5}$ Pediatric Surgery, Bozok University Faculty of Medicine, Yozgat, Turkey

\subsection{6/archdischild-2014-307384.1563}

Background and aims The study was aimed at searching the level of anxiety among mothers with sick children, without chronic illness in an outpatient setting by using Beck anxiety inventory (BAI) and short-health anxiety inventory (HAI) test.

Methods Mothers who brought their ill children to pediatry unit with acute complains were enrolled in the study as trial group. Mothers with children who had no illness were included in the control group drawn from out-of-hospital setting. All subjects took HAI and BAI tests. Results were analysed using SPSS programe.

Results Hundred and twelve trial subjects with average age of $32 \pm 8$ years old and 97 control subjects with average age of 31 \pm 7 years old were included in the study. There wasn't any statistically significance found between groups in respect to age ( $p$ 